\title{
The Effect of Spinal Tap Test on Different Sensory Modalities of Postural Stability in Idiopathic Normal Pressure Hydrocephalus
}

\author{
Katrin Abram ${ }^{a}$ Silvia Bohne ${ }^{b}$ Peter Bublak ${ }^{a}$ Panagiota Karvouniaria, $c$ \\ Carsten M. Klingner ${ }^{a, d}$ Otto W. Witte ${ }^{a}$ Orlando Guntinas-Lichius ${ }^{b}$ \\ Hubertus Axer ${ }^{a, c}$ \\ ${ }^{a}$ Hans Berger Department of Neurology, ${ }^{b}$ Department of Otorhinolaryngology, ${ }^{c}$ Center for \\ Vertigo and Dizziness, and ${ }^{\mathrm{d} B i o m a g n e t i c}$ Center, Jena University Hospital, Jena, Germany
}

\begin{abstract}
Key Words
Normal pressure hydrocephalus - Computerized dynamic posturography - Spinal tap test .

Postural stability
\end{abstract}

\section{Abstract}

Background/Aims: Postural instability in patients with normal pressure hydrocephalus (NPH) is a most crucial symptom leading to falls with secondary complications. The aim of the current study was to evaluate the therapeutic effect of spinal tap on postural stability in these patients. Methods: Seventeen patients with clinical symptoms of NPH were examined using gait scale, computerized dynamic posturography (CDP), and neuropsychological assessment. Examinations were done before and after spinal tap test. Results: The gait score showed a significant improvement $24 \mathrm{~h}$ after spinal tap test in all subtests and in the sum score $(\mathrm{p}<$ 0.003), while neuropsychological assessment did not reveal significant differences $72 \mathrm{~h}$ after spinal tap test. CDP showed significant improvements after spinal tap test in the Sensory Organization Tests $2(p=0.017), 4(p=0.001)$, and $5(p=0.009)$ and the composite score $(p=$ 0.01 ). Patients showed best performance in somatosensory and worst performance in vestibular dominated tests. Vestibular dominated tests did not improve significantly after spinal tap test, while somatosensory and visual dominated tests did. Conclusion: Postural stability in NPH is predominantly affected by deficient vestibular functions, which did not improve after spinal tap test. Conditions which improved best were mainly independent from visual control and are based on proprioceptive functions. 


\section{Introduction}

Idiopathic normal pressure hydrocephalus $(\mathrm{NPH})$ is clinically characterized by the combination of gait disturbance, cognitive decline, and urinary incontinence $[1,2]$. Two of the three clinical symptoms should be apparent for diagnosis, and gait disturbance is regarded as obligatory as it is the earliest and most frequently manifested symptom $[1,3]$. The typical age of onset is between 60 and 80 years of age [4-6]. Neuroimaging generally shows ventricular enlargement with communicating ventricles $[1,7,8]$. In contrast, cortical atrophy is not predominant [9], and tight convexity is a sign of a pressure-grouted subarachnoidal space of the cerebral convexity $[10,11]$.

Clinical variability is high and a large overlap to other neurodegenerative diseases is present. Early diagnosis of NPH allows amelioration of patients' symptoms or at least the inhibition of clinical deterioration e.g. by ventriculoperitoneal shunt implantation $[12,13]$. The spinal tap test is an essential clinical test for evaluating clinical improvement after lumbar drainage of 30-50 ml cerebrospinal fluid (CSF) [14-17]. Following spinal tap test, gait disturbance is the symptom that improves most $[15,18]$. Although cognitive improvement can generally be assessed, inconsistent results between studies are common [17, 19, 20]. Moreover, there is no agreement regarding both the neuropsychological test battery that should be used and also the best time point for neuropsychological assessment after spinal tap test.

A slowly progressive symmetric gait disturbance is the most prominent clinical hallmark of NPH $[20,21]$ and is accompanied by impaired postural stability and the tendency to fall backwards [22]. Falls are frequent [23] and generally result in most harmful injury [24]. In addition, a specific feature is a broad-based gait pattern with outward rotated feet and a diminished height of steps [18]. Posturographic measurements indicate that postural disturbance may be primarily of central vestibular origin [25]. However, peripheral vestibular disturbances (otolith dysfunctions) have also recently been described in NPH patients [26].

To prevent falls, it is essential to understand the nature of postural instability in NPH patients [24]. This prospective, observational study focused on the evaluation of specific features of postural stability using computerized dynamic posturography (CDP) in patients with NPH and its change after spinal tap test.

\section{Subjects and Methods}

\section{Subjects}

Seventeen patients fulfilling the clinical criteria for NPH and planned for spinal tap test were enrolled. The observational study was previously approved by the Ethics Committee of the Friedrich Schiller University Jena (No. 2831-05/10). Written informed consent was obtained from all patients.

Inclusion criteria were at least 2 of 3 clinical criteria of NPH (gait disturbance, cognitive deficit, and urinary incontinence), age $\geq 60$ years, and typical signs of NPH in neuroimaging (ventricular dilation not related to atrophy).

Exclusion criteria comprised secondary hydrocephalus, neuromuscular diseases, vestibular diseases, other neurodegenerative diseases, or CSF pressure at lumbar puncture $>20 \mathrm{~cm} \mathrm{H}_{2} \mathrm{O}$.

Each patient underwent an evaluation of gait disturbance using the gait scale [6], standardized neuropsychological assessment, and CDP before and after spinal tap test. Gait scores were estimated up to $24 \mathrm{~h}$ following spinal tap test and neuropsychological assessment was undertaken up to $72 \mathrm{~h}$ after spinal tap test. 
Abram et al.: The Effect of Spinal Tap Test on Different Sensory Modalities of Postural Stability in Idiopathic Normal Pressure Hydrocephalus

\section{Gait Scale}

The quantitative assessment of gait disturbances was performed by means of the gait scale [6]. It comprises the sum of a walking score (evaluation of various aspects of gait disturbance), time score (time used to walk a 10-meter distance), and step score (number of steps on a walk over $10 \mathrm{~m}$ ), reaching a maximum of 40 points for total inability to walk and 2 points for normal gait.

\section{Neuropsychological Tests}

Neuropsychological assessment consisted of a battery of tests evaluating core cognitive functions as shown in table 1, and lasted about $90 \mathrm{~min}$. Neuropsychological assessment before and after spinal tap test comprised parallel test sets to prevent learning effects. Each raw score was transformed into a C-score, along a normative centile scale with a mean value of 3 , and a standard deviation of 2 . That is, $\mathrm{C}$-scores between 3 and 7 are within the normal range, while scores between 2 and 3 reflect mild, and scores below 2 moderate to severe impairment. The sum of all C-values was used for statistical testing.

\section{Computerized Dynamic Posturography}

CDP (Equi-Test ${ }^{\circledR}$-System, NeuroCom International, Clackamas, Oreg., USA) was used to evaluate different conditions of postural stability. The patient is secured with a belt to prevent falls and stands in a box on a platform which measures the force between the feet and the ground from which the sway can be estimated.

The Sensory Organization Test (SOT) is based on the fact that there are three sensory systems mainly involved in maintaining balance (visual, vestibular, and proprioceptive) [27, 28]. Platform and visual surround can dynamically be changed and eyes can be open or closed, so that six different conditions are used for 6 SOT measures: (1) eyes open, stable surface and visual surround; (2) eyes closed, stable surface and visual surround; (3) eyes open, stable surface, and sway-referenced visual surround; (4) eyes open, sway-referenced surface, and stable visual surround; (5) eyes closed, sway-referenced surface, and stable visual surround; (6) eyes open, sway-referenced surface and visual surround (fig. 1).

The balance score quantifies the sway in the anteroposterior direction between 100 (no sway) and 0 (total loss of balance/fall) for each of the six conditions. Finally, a composite score was calculated, which represents a weighted mean of all SOT scores [29].

In addition, secondary sensory analysis evaluates the disturbance of the different sensory systems taking part in postural stability based on the extent of involvement of the individual sensory system in the different SOT conditions (i.e., visual: SOT 4/SOT 1, somatosensory: SOT 2/SOT 1, vestibular: SOT 5/SOT 1).

\section{Statistics}

IBM SPSS Statistics Version 21 (IBM, Armonk, N.Y., USA) was used for statistical analysis. As Kolmogorov-Smirnov test did not prove normal distribution for many of the variables, paired Wilcoxon sign rank test with a two-sided significance level of $5 \%$ was used to compare measurements and scores before and after tap test. Unpaired Student's t test with a two-sided significance level of 5\% was used to compare a patient group with clinical improvement after tap test with a group of patients without clinical improvement. Here, a difference score between the variables (SOT, gait score, neuropsychological tests) before and after tap test was calculated. Because the study had an exploratory character, no adjustment for multiple testing was performed. 
Abram et al.: The Effect of Spinal Tap Test on Different Sensory Modalities of Postural Stability in Idiopathic Normal Pressure Hydrocephalus

Table 1. Neuropsychological assessment

\begin{tabular}{|c|c|c|}
\hline Test & Description & Abilities measured \\
\hline $\begin{array}{l}\text { Similarities (from Wechsler Adult } \\
\text { Intelligence Scale, WAIS) }\end{array}$ & $\begin{array}{l}\text { Participants are given two words or } \\
\text { concepts and have to provide the } \\
\text { generic term }\end{array}$ & $\begin{array}{l}\text { Abstract verbal reasoning, } \\
\text { semantic knowledge }\end{array}$ \\
\hline $\begin{array}{l}\text { Subtest } 3 \text { of the German } \\
\text { Leistungprüfsystem } \\
\text { (Performance Assessment } \\
\text { System, LPS) }\end{array}$ & $\begin{array}{l}\text { Participants have to identify the } \\
\text { organising principle within a chain of } \\
\text { figures }\end{array}$ & $\begin{array}{l}\text { Inductive nonverbal } \\
\text { reasoning }\end{array}$ \\
\hline $\begin{array}{l}\text { Lexical fluency (from a German } \\
\text { word fluency test, the } \\
\text { Regensburger Wort- } \\
\text { flüssigkeitstest, RWT) }\end{array}$ & $\begin{array}{l}\text { Participants have to find, within a } \\
\text { minute, as many words as possible } \\
\text { beginning with the same letter }\end{array}$ & Executive functions \\
\hline Semantic fluency (RWT) & $\begin{array}{l}\text { Participants have to find, within a } \\
\text { minute, as many words belonging to } \\
\text { the same category }\end{array}$ & Executive functions \\
\hline $\begin{array}{l}\text { Color-word-interference task } \\
\text { (from Nuernberg Aging } \\
\text { Inventory, Nuernberger Alters } \\
\text { Inventar, NAI) }\end{array}$ & $\begin{array}{l}\text { Inhibit prepotent tendency to read a } \\
\text { word, and provide ink color instead }\end{array}$ & Executive functions \\
\hline $\begin{array}{l}\text { Digits forwards (from Wechsler } \\
\text { Memory Scale Revised, WMS-R) }\end{array}$ & $\begin{array}{l}\text { Repeat number sequences in the same } \\
\text { order as presented }\end{array}$ & Short-term memory \\
\hline Digits backwards (WMS-R) & $\begin{array}{l}\text { Repeat number sequences in reversed } \\
\text { order }\end{array}$ & Working memory \\
\hline $\begin{array}{l}\text { Trail Making Test A/B (TMT-A/ } \\
\text { TMT-B) }\end{array}$ & $\begin{array}{l}\text { TMT-A requires an individual to } \\
\text { connect randomly located numbers in } \\
\text { ascending order as rapidly as possible. } \\
\text { TMT-B requires switching between } \\
\text { numbers and letters }\end{array}$ & $\begin{array}{l}\text { Visuomotor speed and } \\
\text { executive functions }\end{array}$ \\
\hline Digit symbol test (WAIS) & $\begin{array}{l}\text { Participants have to assign each digit } \\
\text { to a corresponding symbol as fast as } \\
\text { possible }\end{array}$ & Processing speed \\
\hline $\begin{array}{l}\text { Age-Concentration-Test } \\
\text { (Alters-Konzentrations-Test, } \\
\text { AKT) }\end{array}$ & $\begin{array}{l}\text { Identify visual target stimuli among } \\
\text { similar distractor items }\end{array}$ & Selective attention \\
\hline $\begin{array}{l}\text { CERAD (Consortium to Establish } \\
\text { a Registry for Alzheimer's } \\
\text { Disease) - 10-Item Word List } \\
\text { Learning Task }\end{array}$ & $\begin{array}{l}\text { Three trials of a } 10 \text {-item word list } \\
\text { learning task }\end{array}$ & $\begin{array}{l}\text { Verbal episodic memory, } \\
\text { learning }\end{array}$ \\
\hline CERAD - word list recall & $\begin{array}{l}\text { Delayed recall of the items of the word } \\
\text { list learned before }\end{array}$ & $\begin{array}{l}\text { Verbal episodic memory, free } \\
\text { recall }\end{array}$ \\
\hline CERAD - word list recognition & $\begin{array}{l}\text { Recognition of the items of the word } \\
\text { list learned before }\end{array}$ & $\begin{array}{l}\text { Verbal episodic memory, } \\
\text { recognition }\end{array}$ \\
\hline $\begin{array}{l}\text { CERAD - Boston Naming Test } \\
\text { (BNT) }\end{array}$ & Picture naming & $\begin{array}{l}\text { Visual recognition and word } \\
\text { retrieval }\end{array}$ \\
\hline CERAD - cube copy & Copying a wire cube & Visuoconstructional skills \\
\hline
\end{tabular}


Table 2. Demographics of patients $(\mathrm{n}=17)$

\begin{tabular}{l|l}
\hline Dement Geriatr Cogn Disord Extra 2016;6:447-457 \\
\hline DOI: 10.1159/000450602 & $\begin{array}{l}\text { @ 2016 The Author(s). Published by S. Karger AG, Basel } \\
\text { www.karger.com/dee }\end{array}$ \\
\hline
\end{tabular}

Abram et al.: The Effect of Spinal Tap Test on Different Sensory Modalities of Postural Stability in Idiopathic Normal Pressure Hydrocephalus

\begin{tabular}{|c|c|}
\hline Parameter & Statistics \\
\hline Age, years (mean \pm SD) & $75.7 \pm 7.04$ \\
\hline Range of age, years & $66-85$ \\
\hline \multicolumn{2}{|l|}{ Gender } \\
\hline Female & $6(35.3 \%)$ \\
\hline Male & $11(64.7 \%)$ \\
\hline \multicolumn{2}{|l|}{ Age at onset of gait disturb- } \\
\hline \multirow[t]{3}{*}{ NPH symptoms } & Gait disturbance $(\mathrm{n}=17)$ \\
\hline & Cognitive impairment $(\mathrm{n}=17)$ \\
\hline & Urinary incontinence $(\mathrm{n}=12)$ \\
\hline \multirow[t]{3}{*}{ Comorbidities } & Arterial hypertension $(\mathrm{n}=17)$ \\
\hline & Diabetes mellitus $(\mathrm{n}=9$ ) \\
\hline & Coronary heart disease $(n=3)$ \\
\hline
\end{tabular}

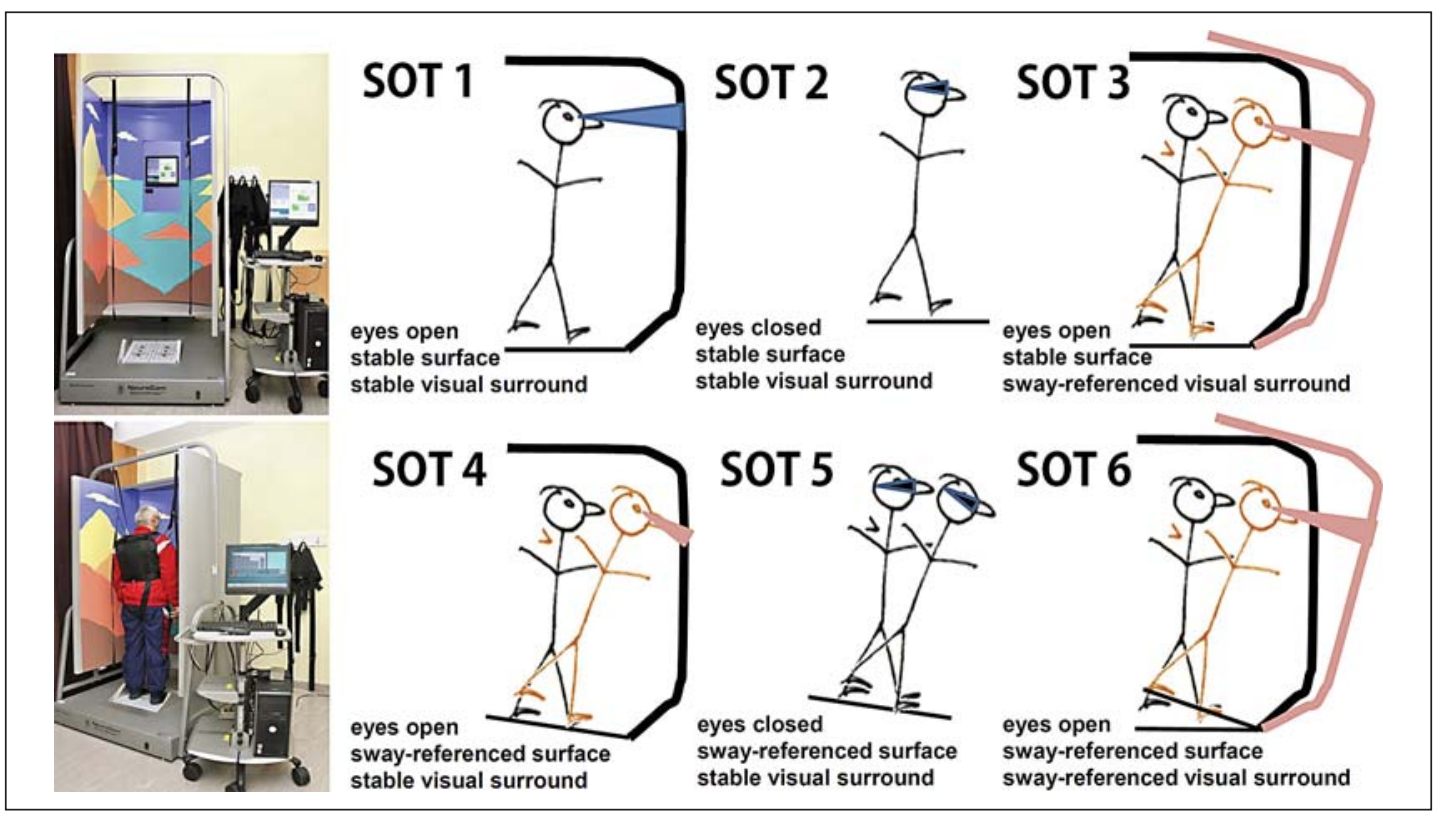

Fig. 1. Conditions of Sensory Organization Test (SOT 1-6). The photos on the left hand side show the CDP system in the neuro-otological laboratory.

\section{Results}

The demographic data of the study population are shown in table 2. CSF pressure as measured by lumbar puncture showed a mean of $15.4 \mathrm{~cm} \mathrm{H}_{2} \mathrm{O}$ with a standard deviation of 4.44. Each patient received a spinal tap test with a drainage of 30-40 ml CSF.

\section{Gait Score}

Each subtest (walking score, step score, and time score) of the gait score as well as the total gait score improved significantly (fig. 2a). 


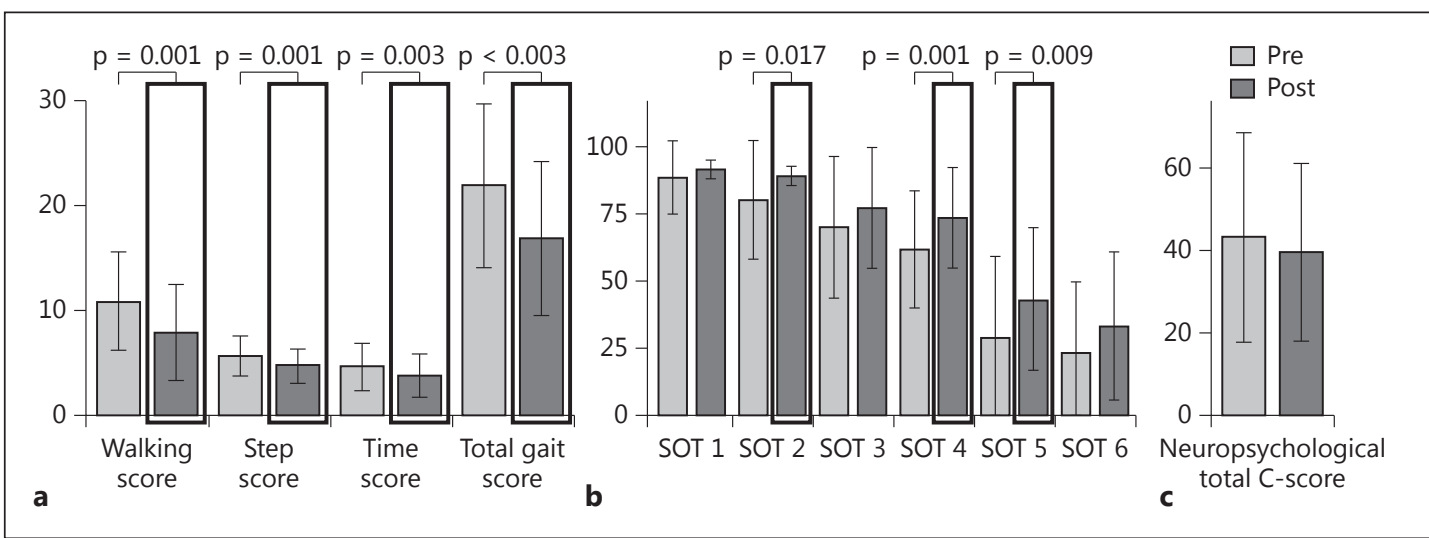

Fig. 2. Gait scores (a), CDP (b), and neuropsychological assessment (c) before and after spinal tap test. Significant differences are marked. Error bars depict 1 standard deviation.

\section{Computerized Dynamic Posturography}

Only 14 patients were analyzed by CDP after spinal tap test. One patient refused the second examination, 2 patients could not be examined with CDP due to a deterioration of general health status. Test scores of CDP became worse with increasing difficulty of the test. The six SOT subtests showed significant improvements between pre- and post-tap test in SOT 2 (eyes closed, stable surface and visual surround), SOT 4 (eyes open, sway-referenced surface, and stable visual surround), and SOT 5 (eyes closed, sway-referenced surface, and stable visual surround). Figure $2 \mathrm{~b}$ shows the results of all SOT subtests. The composite score was significantly improved ( $\mathrm{p}=0.01$ ) after spinal tap test (before spinal tap test: mean 56.4 \pm 24.7 and after spinal tap test: mean $63.5 \pm 16.0$ ).

Sensory analysis revealed the worst performance in vestibular-based subtests, while performance in somatosensory and visual-based subtests was much better (fig. 3). In addition, somatosensory and visual performance significantly improved after spinal tap test, while vestibular performance did not show significant differences between pre- and post-spinal tap test.

\section{Neuropsychological Assessment}

The total C-score of the neuropsychological assessment did not show any statistical difference between pre- and post-spinal tap test (fig. 2b).

\section{Subgroup Analysis}

Patients were evaluated by a neurologist to access the clinical significance of improvements after spinal tap test. Figure 4 shows the difference scores of all test variables according to both groups. Walking score $(p=0.011)$ and step score $(p=0.049)$ showed significant differences between the groups. In CDP, SOT 6 slightly missed significance $(p=0.05)$. No differences were found for the sum of the C-score of the neuropsychological assessment.

\section{Discussion}

The gait score showed a significant improvement after spinal tap test in all subtests as well as in the sum score. This confirms that gait disturbance represents the NPH symptom which improves most and fastest following spinal tap test $[15,21,30,31]$ and is generally 
Fig. 3. Sensory analysis of CDP results.

Fig. 4. Difference scores of test variables in patients with clinical improvement $(\mathrm{n}=11)$ and patients without $(n=6)$.
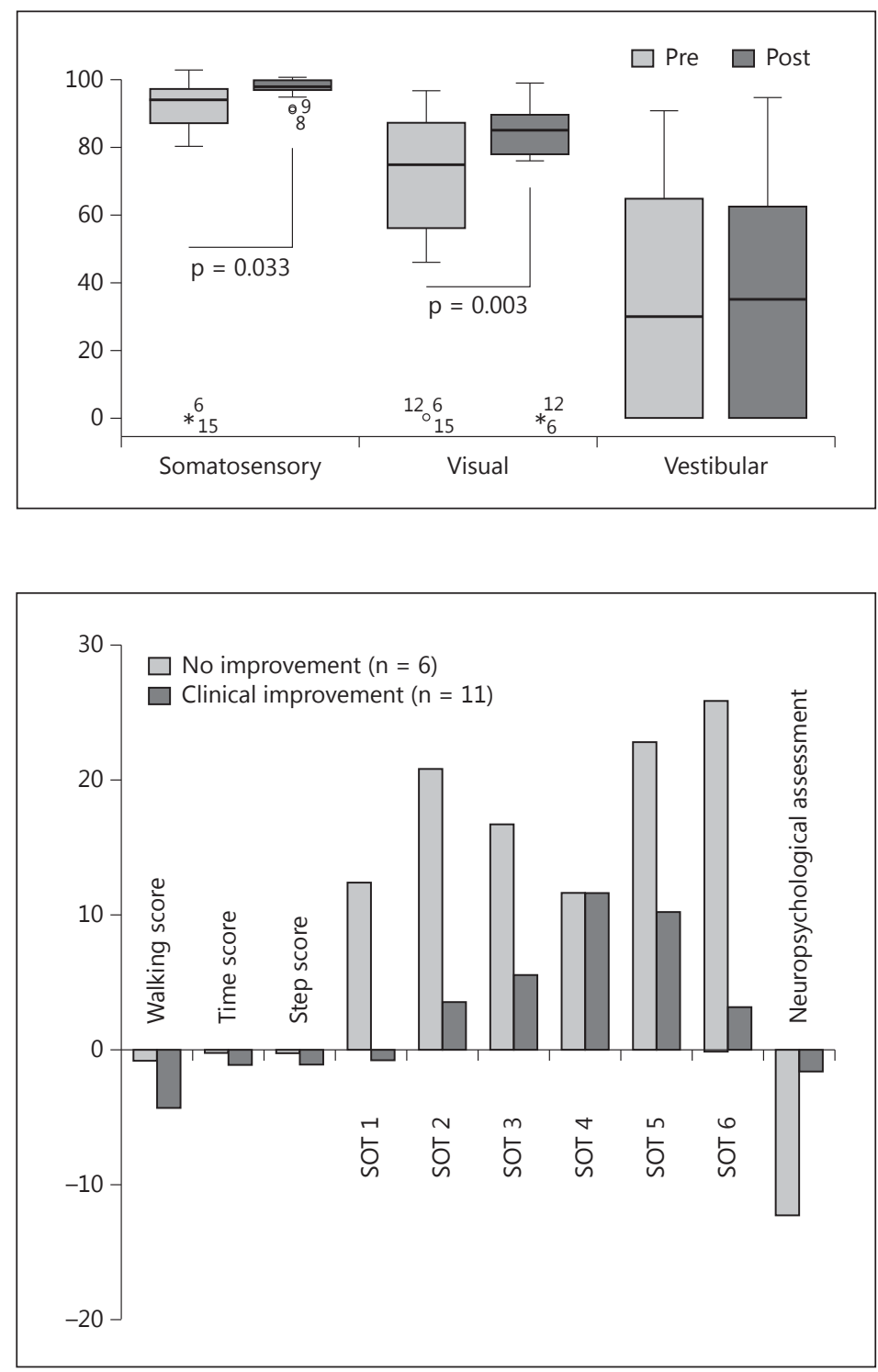

seen as a good marker for prognosis after shunt surgery $[19,30]$. Slowness, short stride and disequilibrium were described as principal features of NPH gait [30] in addition to decreased foot-to-floor clearance and a broad-based gait [15]. After spinal tap test, walking speed, steps for turning, and tendency to fall were most likely to improve [21]. In this context, the gait scale $[6,17]$ is a reliable and valid tool to clinically evaluate gait in NPH patients after spinal tap test.

In contrast to improvements of gait, neuropsychological assessment did not reveal significant changes in a time interval of maximally $72 \mathrm{~h}$ after spinal tap test in the current study. NPH patients show an impairment of frontal lobe functions that are disproportionately severe and memory impairment that is disproportionately mild compared to patients with Alzheimer's disease [32]. Moreover, it has been shown that cognitive impairment is associated with gait disturbance [33].

Several studies found long-term improvement of cognitive functions after shunt surgery [34-37], while others failed to demonstrate such an improvement [14, 20, 38]. However, 
Abram et al.: The Effect of Spinal Tap Test on Different Sensory Modalities of Postural Stability in Idiopathic Normal Pressure Hydrocephalus

comparability between studies is hampered both by the use of different neuropsychological test batteries and different time intervals between intervention and neuropsychological assessment. If cognitive dysfunction persists over more than 2 years before shunt surgery, prognosis for cognitive outcome after shunt surgery is poor [39]. Kubo et al. [40] showed an improvement of the Mini Mental State Examination and gait status 1 week after spinal tap test in NPH patients who were regarded to benefit from CSF tapping according to the idiopathic NPH grading scale. The failed proof of cognitive improvement after spinal tap test in our study may be due to the very short time interval between spinal tapping and neuropsychological assessment. However, the study protocol was designed with focus on postural instability. From another point of view, the results indicate that neurocognitive testing may be not sensitive enough $72 \mathrm{~h}$ after spinal tap test and should therefore be performed after longer time intervals.

CDP showed improvement in SOT 2, 4, and 5 and in the composite score, whilst SOT 1, 3, and 6 did not show significant differences between before and after spinal tap test. In addition, sensory analysis revealed the best performance in somatosensory and the worst performance in vestibular dominated tests. In addition, vestibular dominated tests did not improve significantly after spinal tap test, while somatosensory and visually dominated tests did.

CDP, initially introduced by Nashner in 1987 [29], allows the collection of reliable data on postural stability and balance and the evaluation of the pathological mechanisms involved [41]. CDP and SOT are valid and reliable tests to evaluate postural stability [42] and allow the differentiation of normal and pathological vestibular function [43] with a good test-retest reliability in patients older than 65 years of age $[28,43]$.

Lundin et al. [25] used CDP to study postural stability in patients with idiopathic NPH before and 3 months after shunt surgery. They found poorer preoperative SOT measurements in all subtests compared with healthy individuals. The greatest difference was found in test conditions measuring mainly vestibular function. Three months after shunt surgery, improvement was seen in the weighted composite SOT score, but no significant change was found in any of the SOT conditions.

Our study revealed similar results as greatest impairment was demonstrated in SOT 5 and 6 indicating that the postural disturbance may be dominantly of vestibular origin [25], which was also demonstrated in secondary sensory analysis with predominantly poorest scores in vestibular dominated test situations in our study. In addition, vestibular dominated tests did not show significant improvement after spinal tap test contrary to proprioceptive and visually dominated tests. Generally, at least one operating vestibular organ is needed to perform SOT 5 and 6 [44-48]. Thus, SOT 5 and 6 are the most sensitive test conditions to detect central and/or peripheral vestibular dysfunctions [41]. At first thought, one might expect that impaired vestibular performance is caused by disturbed cerebral processing of vestibular information. However, a recent study has demonstrated a disturbed otolith function in NPH patients [26], so that peripheral vestibular dysfunction may also have a pathophysiological impact on balance functions in NPH. Therefore, it has to be proved whether vestibular rehabilitation strategies may have an additive benefit on postural stability in NPH patients after shunt surgery.

Results from static posturography showed an improvement of postural sway area and sway radius with open as well as with closed eyes in NPH patients after shunt surgery compared to normal controls [49]. NPH patients had a larger sway area and a higher backward directed velocity of center of pressure than normal controls [22]. NPH patients showed more improvement in postural than in motor functions after shunt surgery. Postural function was significantly less in positions with open eyes in the NPH patients than in patients with subcortical arteriosclerotic encephalopathy and healthy controls [22]. In addition, NPH patients swayed more in the sagittal than in the frontal plane and at a higher speed than normal 
controls. In addition, they were aided to a lesser degree by their vision [50]. The subjective visual vertical tilted towards the patients in combination with the pathological sway pattern pointed to a defective internal processing of gravicentric information [50].

In our study, two of the three SOT conditions which improved after spinal tap test were independent from visual stimuli (SOT 2 and 5). In contrast, SOT with open eyes (except SOT 4) did not reveal significantly improved results after spinal tap test. Thus, visual control did not severely influence improvement of balance functions, which may correlate to the hypothesis of Blomsterwall et al. [22] that a misinterpretation of afferent visual stimuli may play a pathophysiological role in NPH patients.

In conclusion, our study reproduced that the gait scale is a good clinical tool to monitor improvement of gait early after spinal tap test in NPH patients. CDP showed improvement in SOT 2, 4, and 5 and the composite score after spinal tap test. The results suggest that the predominant deficit for postural stability is located in the vestibular system. Vestibular functions improved less after spinal tap test than visual and somatosensory functions. In addition, conditions which improved best were mainly independent from visual control and are based on proprioceptive functions. The strong involvement of the vestibular system as well as the lack of effect of spinal tap test on vestibular function raises the question of whether specific vestibular rehabilitation strategies in addition to shunt surgery may have additive beneficial effects on postural stability.

\section{Acknowledgements}

P. Karvouniari was supported by the Interdisciplinary Center for Clinical Research of Jena University Hospital (IZKF Jena, laboratory rotation program). C.M. Klingner and O.W. Witte were supported by BMBF (IRESTRA 16SV7209 and Schwerpunktprogramm BU 1327/4-1). We thank Nasim Krögel for help with language editing.

\section{References}

1 Hakim CA, Hakim R, Hakim S: Normal-pressure hydrocephalus. Neurosurg Clin N Am 2001;12:761-773.

2 Adams RD, Fisher CM, Hakim S, Ojemann RG, Sweet WH: Symptomatic occult hydrocephalus with 'normal' cerebrospinal-fluid pressure. A treatable syndrome. N Engl J Med 1965;273:117-126.

3 Hebb A0, Cusimano MD: Idiopathic normal pressure hydrocephalus: a systematic review of diagnosis and outcome. Neurosurgery 2001;49:1166-1184.

-4 Marmarou A, Young HF, Aygok GA, Sawauchi S, Tsuji O, Yamamoto T, Dunbar J: Diagnosis and management of idiopathic normal-pressure hydrocephalus: a prospective study in 151 patients. J Neurosurg 2005;102:987997.

5 Mori K: Management of idiopathic normal-pressure hydrocephalus: a multiinstitutional study conducted in Japan. J Neurosurg 2001;95:970-973.

6 Boon AJ, Tans JT, Delwel EJ, Egeler-Peerdeman SM, Hanlo PW, Wurzer HA, Avezaat CJ, de Jong DA, Gooskens $\mathrm{RH}$, Hermans J: Dutch normal-pressure hydrocephalus study: prediction of outcome after shunting by resistance to outflow of cerebrospinal fluid. J Neurosurg 1997;87:687-693.

7 Relkin N, Marmarou A, Klinge P, Bergsneider M, Black PM: Diagnosing idiopathic normal-pressure hydrocephalus. Neurosurgery 2005;57(suppl 3):S4-S16.

-8 Sasaki H, Ishii K, Kono AK, Miyamoto N, Fukuda T, Shimada K, Ohkawa S, Kawaguchi T, Mori E: Cerebral perfusion pattern of idiopathic normal pressure hydrocephalus studied by SPECT and statistical brain mapping. Ann Nucl Med 2007;21:39-45.

-9 Holodny AI, Waxman R, George AE, Rusinek H, Kalnin AJ, de Leon M: MR differential diagnosis of normalpressure hydrocephalus and Alzheimer disease: significance of perihippocampal fissures. AJNR Am J Neuroradiol 1998;19:813-819.

10 Hashimoto M, Ishikawa M, Mori E, Kuwana N; Study of INPH on neurological improvement (SINPHONI): Diagnosis of idiopathic normal pressure hydrocephalus is supported by MRI-based scheme: a prospective cohort study. Cerebrospinal Fluid Res 2010; 7:18. 
11 Mataro M, Matarin M, Poca MA, Pueyo R, Sahuquillo J, Barrios M, Junque C: Functional and magnetic resonance imaging correlates of corpus callosum in normal pressure hydrocephalus before and after shunting. J Neurol Neurosurg Psychiatry 2007;78:395-398.

-12 Mori E, Ishikawa M, Kato T, Kazui H, Miyake H, Miyajima M, Nakajima M, Hashimoto M, Kuriyama N, Tokuda T, Ishii K, Kaijima M, Hirata Y, Saito M, Arai H: Guidelines for management of idiopathic normal pressure hydrocephalus: second edition. Neurol Med Chir 2012;52:775-809.

13 Gallia GL, Rigamonti D, Williams MA: The diagnosis and treatment of idiopathic normal pressure hydrocephalus. Nat Clin Pract Neurol 2006;2:375-381.

14 Marmarou A, Bergsneider M, Klinge P, Relkin N, Black PM: The value of supplemental prognostic tests for the preoperative assessment of idiopathic normal-pressure hydrocephalus. Neurosurgery 2005;57 (suppl 3):S17S28.

15 Stolze H, Kuhtz-Buschbeck JP, Drucke H, Johnk K, Diercks C, Palmie S, Mehdorn HM, Illert M, Deuschl G: Gait analysis in idiopathic normal pressure hydrocephalus - which parameters respond to the CSF tap test? Clin Neurophysiol 2000;111:1678-1686.

16 Sand T, Bovim G, Grimse R, Myhr G, Helde G, Cappelen J: Idiopathic normal pressure hydrocephalus: the CSF tap-test may predict the clinical response to shunting. Acta Neurol Scand 1994;89:311-316.

$\rightarrow 17$ Wikkelso C, Andersson H, Blomstrand C, Lindqvist G, Svendsen P: Normal pressure hydrocephalus. Predictive value of the cerebrospinal fluid tap-test. Acta Neurol Scand 1986;73:566-573.

-18 Stolze H, Kuhtz-Buschbeck JP, Drucke H, Johnk K, Illert M, Deuschl G: Comparative analysis of the gait disorder of normal pressure hydrocephalus and Parkinson's disease. J Neurol Neurosurg Psychiatry 2001;70:289-297.

19 Wikkelso C, Andersson H, Blomstrand C, Lindqvist G: The clinical effect of lumbar puncture in normal pressure hydrocephalus. J Neurol Neurosurg Psychiatry 1982;45:64-69.

20 Malm J, Kristensen B, Karlsson T, Fagerlund M, Elfverson J, Ekstedt J: The predictive value of cerebrospinal fluid dynamic tests in patients with the idiopathic adult hydrocephalus syndrome. Arch Neurol 1995;52:783789.

-21 Ravdin LD, Katzen HL, Jackson AE, Tsakanikas D, Assuras S, Relkin NR: Features of gait most responsive to tap test in normal pressure hydrocephalus. Clin Neurol Neurosurg 2008;110:455-461.

-22 Blomsterwall E, Svantesson U, Carlsson U, Tullberg M, Wikkelsö C: Postural disturbance in patients with normal pressure hydrocephalus. Acta Neurol Scand 2000;102:284-291.

23 Haan J, Jansen EN, Oostrom J, Roos RA: Falling spells in normal pressure hydrocephalus: a favourable prognostic sign? Eur Neurol 1987;27:216-220.

-24 Axer H, Axer M, Sauer H, Witte OW, Hagemann G: Falls and gait disorders in geriatric neurology. Clin Neurol Neurosurg 2010;112:265-274.

-25 Lundin F, Ledin T, Wikkelso C, Leijon G: Postural function in idiopathic normal pressure hydrocephalus before and after shunt surgery: a controlled study using computerized dynamic posturography (EquiTest). Clin Neurol Neurosurg 2013;115:1626-1631.

-26 Böttcher N, Bremova T, Feil K, Heinze C, Schniepp R, Strupp M: Normal pressure hydrocephalus: increase of utricular input in responders to spinal tap test. Clin Neurophysiol 2016;127:2294-2301.

-27 Wrisley DM, Stephens MJ, Mosley S, Wojnowski A, Duffy J, Burkard R: Learning effects of repetitive administrations of the sensory organization test in healthy young adults. Arch Phys Med Rehabil 2007;88:1049-1054.

-28 Ford-Smith CD, Wyman JF, Elswick RK Jr, Fernandez T, Newton RA: Test-retest reliability of the sensory organization test in noninstitutionalized older adults. Arch Phys Med Rehabil 1995;76:77-81.

29 Nashner LM, Peters JF: Dynamic posturography in the diagnosis and management of dizziness and balance disorders. Neurol Clin 1990;8:331-349.

-30 Bugalho P, Guimaraes J: Gait disturbance in normal pressure hydrocephalus: a clinical study. Parkinsonism Relat Disord 2007;13:434-437.

31 Fisher CM: Hydrocephalus as a cause of disturbances of gait in the elderly. Neurology 1982;32:1358-1363.

-32 Ogino A, Kazui H, Miyoshi N, Hashimoto M, Ohkawa S, Tokunaga H, Ikejiri Y, Takeda M: Cognitive impairment in patients with idiopathic normal pressure hydrocephalus. Dement Geriatr Cogn Disord 2006;21:113-119.

-33 Miyoshi N, Kazui H, Ogino A, Ishikawa M, Miyake H, Tokunaga H, Ikejiri Y, Takeda M: Association between cognitive impairment and gait disturbance in patients with idiopathic normal pressure hydrocephalus. Dement Geriatr Cogn Disord 2005;20:71-76.

-34 Yamamoto D, Kazui H, Wada T, Nomura K, Sugiyama H, Shimizu Y, Yoshiyama K, Yoshida T, Kishima H, Yamashita F, Yoshimine T, Takeda M: Association between milder brain deformation before a shunt operation and improvement in cognition and gait in idiopathic normal pressure hydrocephalus. Dement Geriatr Cogn Disord 2013;35:197-207.

35 Raftopoulos C, Deleval J, Chaskis C, Leonard A, Cantraine F, Desmyttere F, Clarysse S, Brotchi J: Cognitive recovery in idiopathic normal pressure hydrocephalus: a prospective study. Neurosurgery 1994;35:397-404.

-36 Klinge P, Ruckert N, Schuhmann M, Dorner L, Brinker T, Samii M: Neuropsychological testing to improve surgical management of patients with chronic hydrocephalus after shunt treatment. Acta Neurochir Suppl 2002;81:51-53.

-37 Duinkerke A, Williams MA, Rigamonti D, Hillis AE: Cognitive recovery in idiopathic normal pressure hydrocephalus after shunt. Cogn Behav Neurol 2004;17:179-184.

-38 Thomsen AM, Borgesen SE, Bruhn P, Gjerris F: Prognosis of dementia in normal-pressure hydrocephalus after a shunt operation. Ann Neurol 1986;20:304-310. 
39 Graff-Radford NR, Godersky JC, Jones MP: Variables predicting surgical outcome in symptomatic hydrocephalus in the elderly. Neurology 1989;39:1601-1604.

40 Kubo Y, Kazui H, Yoshida T, Kito Y, Kimura N, Tokunaga H, Ogino A, Miyake H, Ishikawa M, Takeda M: Validation of grading scale for evaluating symptoms of idiopathic normal-pressure hydrocephalus. Dement Geriatr Cogn Disord 2008;25:37-45.

41 Black FO: What can posturography tell us about vestibular function? Ann NY Acad Sci 2001;942:446-464.

-42 Monsell EM, Furman JM, Herdman SJ, Konrad HR, Shepard NT: Computerized dynamic platform posturography. Otolaryngol Head Neck Surg 1997;117:394-398.

-43 Hamid MA, Hughes GB, Kinney SE: Specificity and sensitivity of dynamic posturography. A retrospective analysis. Acta Otolaryngol Suppl 1991;481:596-600.

44 Black FO, Gianna-Poulin C, Pesznecker SC: Recovery from vestibular ototoxicity. Otol Neurotol 2001;22:662671.

45 Black FO, Shupert CL, Horak FB, Nashner LM: Abnormal postural control associated with peripheral vestibular disorders. Prog Brain Res 1988;76:263-275.

46 Paloski WH, Black FO, Reschke MF, Calkins DS, Shupert C: Vestibular ataxia following shuttle flights: effects of microgravity on otolith-mediated sensorimotor control of posture. Am J Otol 1993;14:9-17.

-47 Horak FB, Shumway-Cook A, Crowe TK, Black FO: Vestibular function and motor proficiency of children with impaired hearing, or with learning disability and motor impairments. Dev Med Child Neurol 1988;30:64-79.

-48 Wolfson L, Whipple R, Derby CA, Amerman P, Murphy T, Tobin JN, Nashner L: A dynamic posturography study of balance in healthy elderly. Neurology 1992;42:2069-2075.

-49 Czerwosz L, Szczepek E, Blaszczyk JW, Sokolowska B, Dmitruk K, Dudzinski K, Jurkiewicz J, Czernicki Z: Analysis of postural sway in patients with normal pressure hydrocephalus: effects of shunt implantation. Eur J Med Res 2009;14(suppl 4):53-58.

-50 Blomsterwall E, Frisén L, Wikkelsö C: Postural function and subjective eye level in patients with idiopathic normal pressure hydrocephalus. J Neurol 2011;258:1341-1346. 